\title{
La puerta norte del "sueño chileno". Ciudad fronteriza, asentamiento de migrantes y precariópolis en Arica, Chile
}

\section{The north door of the "Chilean dream". Border city, migrant settlement and precariopolis in Arica, Chile}

Recibido el 5 de febrero de 2021. Aceptado el 12 de mayo de 2021. Publicado el 19 de mayo de 2021.

*Autor para correspondencia: Rodrigo Hidalgo Dattwyler. Correo electrónico: rodrigohidalgogeo@gmail.com

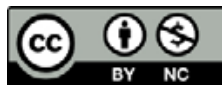

Esta obra está protegida bajo una Licencia Creative Commons Atribución-NoComercial 4.0 Internacional.

\author{
Rodrigo Hidalgo Dattwyler* (D) https://orcid.org/0000-0001-6092-1547 \\ Carlos Vergara Constela ${ }^{a}$ (D) https://orcid.org/0000-0001-8737-7828 \\ Miguel Felipe González Rodríguez ${ }^{a}$ (D) https://orcid.org/0000-0002-9169-9093
}

${ }^{a}$ Pontificia Universidad Católica de Chile, Instituto de Geografía, Santiago, Chile, correo electrónico: rodrigohidalgogeo@gmail.com, cdvc87@gmail.com, mgonzalezro.fe@gmail.com

\section{Resumen}

Se presenta un análisis de Arica (Chile) en su condición de ciudad frontera. Con el objetivo de describir y analizar la movilidad migratoria de la ciudad de Arica y los asentamientos donde reside la población migrante, se plantea una discusión centrada en bibliografía latinoamericana sobre ciudades frontera, movilidad, migración y asentamientos humanos, donde se resaltan las categorías de gueto y precariópolis. Se aplicaron técnicas de producción de datos que combinan producción estadística de fuentes oficiales en conjunto con observación y análisis documental. Los resultados muestran que la población migrante es mayoritariamente peruana, boliviana y tiende a localizarse en tres grandes áreas de la ciudad: norte, sur y valle de Azapa. Se indaga específicamente en el caso de Cerro Chuño, el cual es problematizado como asentamiento migrante bajo la discusión de las expresiones de gueto y precariópolis.

Palabras clave: ciudad frontera, migraciones, precariedad, Cerro Chuño.

\section{Abstract}

An analysis of Arica (Chile) is presented as a border city. In order to describe and analyze the migratory mobility of the city of Arica and the settlements where the migrant population resides, a discussion centered on Latin American bibliography on border cities, mobility, migration and human settlements is proposed, where we resort to the categories of the ghetto and precarious city. Data production techniques were applied combining statistical production from official sources together with observation and documentary analysis. The results show that the migrant population is mainly Peruvian, Bolivian and tends to be in three large areas of the city: north, south and valley of

CÓMO CITAR: Hidalgo Dattwyler, R., Vergara Constela, C. \& González Rodríguez, M. F. (2021). La puerta norte del "sueño chileno". Ciudad fronteriza, asentamiento de migrantes y precariópolis en Arica, Chile [The north door of the "Chilean dream". Border city, migrant settlement and precariopolis in Arica, Chile] Estudios Fronterizos, 22, e070. https://doi.org/10.21670/ref.2107070 
Azapa. It is specifically investigated in the case of Cerro Chuño, which is problematized as a migrant settlement, discussing the expression of ghetto and precarious city.

Keywords: border city, migrations, precariousness, Cerro Chuño.

\section{Introducción}

En las últimas décadas, Chile experimentó un importante fenómeno migratorio. Solo entre 2018 y 2019 la población extranjera aumentó casi 20\%, al pasar de 1250365 a 1442522 (Instituto Nacional de Estadísticas [INE] \& Departamento de Extranjería y Migración [DEM], 2020). El caso chileno, como se analiza en términos generales y en específico para la ciudad fronteriza de Arica, se caracteriza por ser intenso en un corto número de años —duplicación de esa población entre 2014-2019- según cifras oficiales (INE \& DEM, 2020); lo que detona efectos sobre las distintas estructuras socioeconómicas, productivas y territoriales del país.

En este texto el enfoque es en la producción espacial donde se materializan estas migraciones, especialmente en los márgenes de la ciudad; en lugares ensombrecidos por las bonanzas de la globalización neoliberal (Sassen, 2016a, 2016b). En este sentido, las causas de las movilidades de la población están imbricadas entre la esfera política de los Estado nación y la gobernanza de las grandes corporaciones empresariales, que tensionan lo global y lo local (Sassen, 2003). Estas centralidades del poder constituyen la esfera geopolítica contemporánea que provoca expresiones de una migración antes no observada, en contextos a veces apocalípticos, que implican desde el cambio climático y pérdida del hábitat, que configuran escenarios de crisis humanitaria (Sassen, 2016b).

Las expresiones urbanas de estas movilidades humanas desembocan, muchas veces, en la densificación o formación de asentamientos precarios (Canales et al., 2019; Mora, 2009), con la formación de guetos y espacios de confinamiento de población migrante. En esos espacios se manifiestan modos de habitar móviles que tienden a una permanencia muchas veces no imaginada para las personas involucradas.

En este contexto, el trabajo que se presenta está referido a la ciudad de Arica. Una urbe fronteriza del norte de Chile que bordea los 221000 habitantes y que desde los últimos años de la década de 2000 ha recibido a una considerable proporción de migrantes. Al tener esta condición de borde, se generan espacios de "espera" para personas que, en la búsqueda del mítico "sueño chileno", llegan al país con la expectativa de tener un buen empleo y mejores condiciones de vida. En ese trayecto, la población migrante tiene originalmente como destino la capital Santiago u otras urbes del norte, donde Arica es una ciudad predominantemente de paso.

En el devenir de su movilidad, muchos se quedan en tránsito y comienzan a engrosar a las masas empleadas precarizadas que habitan infravivienda o reciclan conjuntos de vivienda subsidiada construidos en la década de 1990. El caso específico que se analiza es el conjunto habitacional Cerro Chuño, ubicado en la entrada norte de la ciudad, el cual se estudia como ejemplo paradigmático del proceso mencionado. Se proponen los conceptos de precariópolis (Hidalgo, 2007) y gueto (Wacquant, 2010) para analizar la materialidad de estos espacios que se vinculan a la realidad chilena de los efectos de la política de vivienda subsidiada. 
A pesar de su posición periférica y de frontera, Arica expresa el reescalamiento (Valdebenito \& Navarro, 2019) que tienen las ciudades de tamaño medio o inferior que la urbanización mundial está desarrollando, producto del reordenamiento de la economía política global. De esta forma, el objetivo de este trabajo es describir y analizar la movilidad migratoria de la ciudad de Arica y los asentamientos donde residen los migrantes, para especificar cómo han producido su espacio habitado, a partir de las categorías de precariópolis y gueto que asumen en Arica.

De este modo, se presenta la propuesta metodológica de investigación para luego establecer las definiciones de ciudades fronterizas, asentamientos y movilidades migrantes. A continuación, se abordan los conceptos de gueto y precariópolis, asociados a la urbanización y producción de espacio. Se analizan la estructura y dinámica de la movilidad migratoria en Arica, para finalizar con el análisis del caso de Cerro Chuño y las formas de emplazamiento de esa población en la periferia de la ciudad.

\section{Metodología}

El diseño metodológico es de carácter mixto. Se hace uso de técnicas cuantitativas y cualitativas, puesto que la complejidad de la problemática abordada obliga a superar falsas dicotomías que estructuran la forma de hacer investigación en las ciencias sociales (Bourdieu et al., 2000). Bajo esta lógica, las técnicas de producción de datos utilizadas fueron la estadística descriptiva, la observación y el análisis documental (Tabla 1).

El análisis estadístico se hizo con base en dos fuentes: el registro anual del Departamento de Extranjería y Migración y el Censo de Población y Vivienda. Estas permitieron apreciar una panorámica longitudinal de la dinámica migratoria de Arica, al distinguir nacionalidades, sexo, edad y capitales educativos. A esto se le sumó la construcción de índices sintéticos para indagar en diferencias espaciales de la migración. Se aplicó un índice de hacinamiento de hogares y un índice de calidad de la vivienda, ambos facilitaron apreciar la distribución de estas variables, según la división censal que ocupa el Estado de Chile en la ciudad de Arica.

La producción estadística fue complementada con la obtención de datos de carácter cualitativo. En este punto resultó clave la observación en terreno de estos espacios, puesto que esta técnica permite apreciar la experiencia de habitar el lugar y la realización de la vida cotidiana, al contemplar su dinámica inmanente (Pellicer et al., 2013). Con base en lo planteado por Guasch (1996), se definió el escenario de observación y la estrategia de inserción. De acuerdo con el primer punto, se realizó observación indirecta del espacio urbano de la ciudad de Arica. Respecto a lo segundo, se accedió a Cerro Chuño en conjunto a un informante clave, quien es habitante de una población contigua. Esto permitió pasar relativamente desapercibidos, lo que posibilitó la construcción de notas de campo y la captura de imágenes fotográficas que permitieron hacer una idea sobre el deterioro urbano del barrio, sus características paisajísticas, esbozar el modo de habitar en ella y la relación que tiene con el resto de la ciudad. 
Tabla 1. Técnicas, datos y productos

\begin{tabular}{|c|c|c|c|}
\hline \multicolumn{2}{|c|}{$\begin{array}{l}\text { Técnica de pro- } \\
\text { ducción de datos }\end{array}$} & Procedimiento & Especificidades y uso \\
\hline & $\begin{array}{l}\text { adística } \\
\text { scriptiva. }\end{array}$ & $\begin{array}{l}\text { 1.1) Estadística univariada. } \\
\text { 1.2) Cruce de variables. } \\
\text { 1.3) Construcción de índices } \\
\text { sintéticos: hacinamiento y } \\
\text { calidad de vivienda. }\end{array}$ & $\begin{array}{l}\text { 1.1) Flujo migratorio según año y nacionalidad. } \\
\text { 1.2) Relación de población migrante según zona de la } \\
\text { ciudad (distrito censal). } \\
\text { 1.3) El índice de hacinamiento implica la división de la } \\
\text { totalidad de habitaciones que son ocupadas exclusiva- } \\
\text { mente para dormir con el total de la población del ho- } \\
\text { gar. El estándar ocupado como frontera del hacinamien- } \\
\text { to es un máximo } 3.5 \text { personas por habitación. De ahí en } \\
\text { más, se considera hacinamiento. } \\
\text { El índice de calidad de la vivienda contempla tres vari- } \\
\text { ables del Censo de Población y Vivienda: materialidad } \\
\text { del techo, muro y suelo de la vivienda, donde se hace } \\
\text { una segmentación entre los hogares que poseen mate- } \\
\text { rialidad precaria y quiénes no. Luego, la población que } \\
\text { sí posee buena materialidad se divide sobre el total de } \\
\text { los hogares. A continuación, se realiza una sumatoria de } \\
\text { cada una de estas variables y se divide por tres, lo que } \\
\text { genera un índice que va entre } 0 \text { y } 1 \text {, donde } 0 \text { significa } \\
\text { una mayor precariedad y } 1 \text { la ausencia de esta. }\end{array}$ \\
\hline 2) & Observación. & $\begin{array}{l}\text { Definición de escenarios de ob- } \\
\text { servación según división de la } \\
\text { ciudad por macro zonas (cen- } \\
\text { tro, norte, sur, periurbano). } \\
\text { Especificación de observación } \\
\text { para población Cerro Chuño. }\end{array}$ & $\begin{array}{l}\text { Caracterización paisajística general: tipología de vivien- } \\
\text { da; localización de infraestructura, equipamiento y ser- } \\
\text { vicios en estructuras zonales y/o barriales; dinámicas y } \\
\text { flujos de población según acceso y tránsitos. Aplicación } \\
\text { de análisis de contenido cualitativo a datos producidos. }\end{array}$ \\
\hline 3) & $\begin{array}{l}\text { Revisión do- } \\
\text { cumental. }\end{array}$ & $\begin{array}{l}\text { Recopilación de fuentes de } \\
\text { prensa, documentos de organi- } \\
\text { zaciones no gubernamentales, } \\
\text { agencias gubernamentales y } \\
\text { documentos audiovisuales ref- } \\
\text { erentes a problemática de po- } \\
\text { blación Cerro Chuño. }\end{array}$ & $\begin{array}{l}\text { Caracterización general de la problemática de Cerro } \\
\text { Chuño donde se revisa lógica del tratamiento de pren- } \\
\text { sa, voces de la población que genera relato histórico y } \\
\text { mecanismos usados por organizaciones no gubernamen- } \\
\text { tales y el Estado. }\end{array}$ \\
\hline
\end{tabular}

Fuente: Elaboración propia

Por último, se realizó una revisión de documentación pública sobre el conflicto particular de Cerro Chuño, donde se repasaron noticias emanadas por la prensa local (periódicos El Morrocotudo y Arica al Día), informes de ONG (Instituto Nacional de Derechos Humanos) y catastros de agencias ministeriales (Ministerio de Vivienda y Urbanismo). Todos estos datos fueron sometidos a un análisis de contenido cualitativo, trabajado con base en categorías y códigos extraídos de los textos revisados.

\section{Ciudades fronterizas: tipologías, asentamientos y movilidad migrante}

Las ciudades fronterizas corresponden a una categoría de urbes complejas, cuestión que se expresa en su funcionalidad, forma y diversidad socio productiva. Así, se entiende 
que las ciudades fronterizas son urbanizaciones donde el Estado, como vector de organización territorial, exacerba y condensa el modelo político, económico y social. En este sentido, estas se definen por su posición geográfica, interacciones de las sociedades que habitan de uno y otro lado de la frontera, por los flujos y fijos que producen una forma urbana en los límites y por la escala que se utiliza (Steiman, 2012; Zarate, 2012).

Estas suelen establecerse como ciudades de paso para los migrantes, donde en muchas ocasiones la detención posee una temporalidad mayor debido a que se encuentran actividades laborales, se muestran ventajas, o hay limitaciones de carácter político, económico o legal que impiden mayor dinamización de la movilidad (Coubès et al., 2020; Alarcón, 2019; Mendoza, 2014).

Las investigaciones de ciudades fronterizas son aparentemente recientes, las cuales corresponden al campo de los estudios fronterizos. Estas, principalmente se han abocado al análisis de las diferencias del dinamismo económico a uno y otro lado de fronteras nacionales, en relación con las áreas de urbanización común que responden a estas dinámicas (Alegría, 2009; Herzog, 1991).

En algunos casos, se producen metrópolis transfronterizas las cuales comparten problemas comunes (Herzog, 1991), que desafían las políticas convencionales de los estados nacionales. Este fenómeno es observable en las ciudades fronterizas de México y Estados Unidos, y también entre países de América Latina, los cuales deben afrontar las consecuencias de la intensa movilidad que se genera en estos espacios (Sohn, 2014; Steiman, 2012; Brites, 2018).

En América del Sur, una de las derivaciones del concepto metrópolis transfronterizas es el de ciudades gemelas o ciudades binacionales (Ehlers et al., 2001). Estas permiten describir el crecimiento del espacio urbano y las relaciones culturales entre quienes habitan esos lugares. Usada desde una perspectiva operativa, las ciudades gemelas posibilitan interrogarse por las políticas estatales en la frontera, las diferentes escalas socioespaciales y los fenómenos asociados a la interacción social y la movilidad que se produce entre ellas (Steiman, 2012).

Estudios tales como el de Posadas-Encarnación en la frontera de ArgentinaParaguay, y en la triple frontera de Brasil, Paraguay y Argentina — donde se instaló la hidroeléctrica de Itapú-, dan cuenta de los efectos espaciales, sociales y ambientales de la construcción de megaproyectos extractivistas y la intensificación del neoliberalismo (Brites \& Catullo, 2016; Brites, 2018; Souza \& Brites, 2017). Uno de los aspectos relevantes para los estudios de estos espacios corresponde al transporte de mercancías y la movilidad de personas, así como también el tráfico ilegal de productos, narcotráfico, trata de personas, migración fuera del marco normativo y violencia (Espín, 2013; Dorfman, 2015; Trejos, 2015; Dammert \& Bensús, 2017).

En este contexto, se conforma una especificidad fronteriza que se caracteriza en tres puntos: no hay una ecología urbana única, los mercados transfronterizos no están integrados y existen profundas diferencias en la planificación y gestión de las ciudades (Alegría, 2009). Por ejemplo, Hiernaux (1994) ha evidenciado que las políticas regionales de desarrollo económico fronterizo con la instalación de industrias maquiladoras potencian la atracción migratoria interna del país a estas ciudades, lo que se muestra como uno de los factores de crecimiento urbano.

En esta dimensión, si bien se producen intercambios entre ambos lados de la frontera, estos son un efecto de los flujos financieros y multinacionales que forman espacios "ganadores" y otros "perdedores", cuyos efectos se observan en distintos usos y escalas. En lo residencial, los fraccionamientos cerrados en las periferias de las 
ciudades representan la contradicción en el habitar generado por la desigualdad del desarrollo económico, que se observa, por ejemplo, en la frontera mexicana (Méndez et al., 2005; Enríquez, 2007; Peña, 2015).

Esto último, cambios en el hábitat y habitar, no solo toma forma en dichos espacios en que residen clases medias y altas, que son originarias de esos lugares o son parte de la movilidad laboral de mejores estándares socioeconómicos de los mismos países, sino que también arriban migrantes nacionales o extranjeros a los asentamientos precarios, muchos de ellos de carácter transitorio con tendencia a la transformación en permanentes (Canales et al., 2019; Mora, 2009). Así como se levantan nuevos núcleos habitacionales, también se densifican algunos ya existentes. En este último caso existe un mercado de alquiler que se acomoda a esta demanda, reflejado en arriendo de cuartos o camas y techo sin provisión de servicios (Fernández Niño et al., 2018; Cordero et al., 2019).

Ejemplos de lugares los encontramos en todo el orbe. En Europa, está el caso reciente de Calais en Francia, cercano al Canal de Suez, que se constituyó en un símbolo de la precarización de un asentamiento formado por la crisis de los migrantes provenientes del conflicto de Siria y el Estado Islámico, los cuales tenían como destino el Reino Unido (Sassen, 2016b). En un contexto distinto - pero también de crisis humanitaria- está el caso de la columna de caminantes centroamericanos que buscan el "sueño americano". En su camino se suman a lugares de refugio o asentamientos precarios de la periferia de las ciudades fronterizas mexicanas (Canales et al., 2019; Cordero et al., 2019).

Subyacente a las dinámicas descritas ocurre el fenómeno global de la movilidad, entendida no solo como el proceso migratorio implícito a las ciudades, sino como la condición actual de movimientos de bienes, servicios, ideas, personas e intercambios en la superficie terrestre, que modifican e instalan una velocidad transformadora no observada antes en el devenir de la humanidad (Salazar, 2019).

La movilidad se ha intensificado por mayor dinamización económica en el marco de la globalización mundial capitalista, para generar transformaciones espaciales (Martínez Pizarro, 2000; Muñoz Jumilla, 2002), que involucran desde los viajes diarios pendulares en las grandes ciudades, pasando por los cambios de residencia en su interior, hasta fenómenos de escala interregional, que pueden estar motivados por desplazamientos al trabajo, estudio y/o turismo, entre otros aspectos (Módenes, 2008; Rodríguez \& Espinoza, 2012).

Incluso la movilidad migrante de carácter más precaria articula espacios residenciales con diferentes grados de transitoriedad en zonas de la ciudad que tienen un nivel de deterioro mayor. Por ejemplo, Jiménez (2017) analiza la estructuración de "guetos migrantes" en poblaciones relativamente abandonadas en Santiago de Chile, o Schiappacasse (2008) indaga en la producción de segregación residencial socioeconómica y el confinamiento migrante. En este marco, se requiere una revisión general del concepto de gueto. Su relación con la precariópolis, concepto utilizado para describir las zonas urbanas de relegación producidas por la política de vivienda subsidiada chilena, lo que puede entregar herramientas para pensar en la conformación de espacios como la periferia ariqueña y Cerro Chuño en particular. 


\section{Las categorías de gueto y precariópolis como base del análisis empírico}

El concepto de gueto tiene una larga tradición en los estudios urbanos y se ha aplicado a diversas realidades de la sociedad contemporánea, desde los guetos judíos en Europa hasta los de afroamericanos en Norte América (Wacquant, 2013; Sternberg, 2017). Con más de 500 años de uso, la palabra tiene su origen en el idioma italiano. Etimológicamente se refiere a un lugar de fundición de metales. El origen habría estado en un barrio de Venecia especializado en esa actividad. La palabra explicaba separación y encerramiento, según establece el diccionario etimológico de Pianigiani de 1907, cuestión que se materializó en el confinamiento de la comunidad hebrea de Venecia en 1516, donde judíos italianos y alemanes fueron excluidos en una zona aislada de la ciudad (Wacquant, 2013).

Wacquant $(2001,2010,2013)$, en un debate no acabado, postula que un gueto es un aparato socioespacial de segmentación y control etnorracial, expresión de la desigualdad y fragmentación de la mano de obra asalariada. Así, el gueto es un dispositivo institucional que utiliza al espacio para conjugar dos destinos antinómicos: maximizar beneficios materiales extraídos a un grupo considerado "contaminado", y minimizar todo contacto íntimo con esos mismos miembros. Como tal, el gueto implica dos caras: por una parte, cumple funciones opuestas para los grupos cercados y los no cercados, a los que une en una relación de dependencia asimétrica. Por otra, el confinamiento y el cierre no implican la ausencia de integración y protección interna. El aislamiento exterior intensifica el contacto social y las formas culturales hacia adentro (Wacquant, 2010).

Para que surja el gueto, el confinamiento espacial ha de ser impuesto y debe tener una serie distintiva y duplicativa de instituciones que permitan al grupo encerrado reproducirse dentro del perímetro. El gueto es una máquina de producción de identidades manchadas, aunque la producción de un estigma también puede devenir en un aumento del orgullo colectivo de quienes son dañados simbólicamente (Wacquant, 2010).

El gueto en América Latina está asociado a las condiciones de vida urbana de las clases trabajadoras. Existe una tendencia a ejemplificar el gueto con la marginalidad y aislamiento habitacional que esos grupos de personas resisten (Sabatini \& Brain, 2008; Delfino, 2012). Los estudios tienden a enfatizar los indicadores cuantitativos que los representan en términos de ingreso y educación (Moreno-Izquierdo \& Lucero, 2010), y sus características demográficas preponderantes (Saraví, 2020). Por lo mismo, lo que resta es profundizar en la producción del espacio y la morfología que en términos socioespaciales el gueto dibuja en las ciudades. Como señala Carlos (2007), el gueto urbano es efecto de la relación entre morfología social y jerarquía espacial, que segrega grupos en el tejido urbano donde se producen formas de apropiación, uso y constitución identitaria.

De lo anterior, se entiende en este estudio que la categoría de gueto es un espacio de la ciudad habitado por población con características comunes donde, más allá de lo pluriétnico, existe un origen similar en sus estrategias de sobrevivencia y en sus modos de vida. Al mismo tiempo, este es un espacio de confinamiento, que comienza siendo asumido como pasajero, pero puede constituirse como fijo y permanente.

Esos lugares se caracterizan por un hábitat esencialmente precario. En la realidad chilena, la conceptualización de la precariópolis ha permitido pensar la producción de 
estos espacios. Entendida como complementaria al gueto, es una acepción descriptiva y analítica de las formas urbanas producidas por la marginalidad y sujetos precarios que habitan bajo estigmas sociales en los contextos neoliberales.

La precariópolis originalmente se asocia a los conjuntos de vivienda que construye el Estado en la periferia de las ciudades, donde otorga acceso a los servicios de urbanización (sanidad, electricidad y vialidad) pero niega el acceso a la ciudad bien equipada. Es la urbanización sin ciudad que genera y alberga vidas precarias, marcadas por la ausencia de valores de seguridad humana, más allá de la capacidad económica y de consumo de los residentes (Hidalgo, 2007, 2018).

El acceso a la vivienda por inmigrantes informales queda atrapado entre la especulación de quienes manejan mercados del alquiler o compraventa y la necesidad inmediata de supervivencia asociados a la condición de pobreza, que los excluye de los procesos regulares de acceso a los servicios. Así, el concepto de precariópolis dentro de una ciudad frontera requiere amplificarse para describir la condición migrante en relación con el espacio habitado y el despliegue de estrategias y prácticas para localizarse y acceder a una vivienda, más allá de la formalidad del mecanismo.

Esta condición de precariedad ubica a la persona en una relación asimétrica definida por la constante inseguridad. La constante incertidumbre y sensación de peligro es una regla contingente, no es la excepción. Así, se allana el terreno para que los gobiernos reproduzcan políticas securitarias de control de población. Para Lorey (2016), la precariedad no puede traspasar cierto umbral, de lo contrario provocaría la posibilidad de insurgencia. Allí se instala el Estado: justamente para gobernar en aquel umbral.

Esta forma de precariedad está vinculada a las trayectorias vitales de personas omitidas y subsumidas en las formas de producción capitalista; de la inseguridad planetaria que plantea Sassen (2016b), y que identifican a seres humanos que quedan expuestos a la desigualdad, a su condición de pasajeros en tránsito y de recicladores constantes de sus condiciones de vida, sin llegar a ser reconocidos por el sistema de reproducción social imperante (Butler, 2006).

\section{Arica, ciudad de frontera: flujos recientes de la dinámica migratoria}

La ciudad de Arica ocupa una posición periférica en el contexto chileno. Es la capital de la región de Arica y Parinacota, en extremo norte del país, unidad políticoadministrativa de reciente creación en 2008 (González \& Ovando, 2010). La ciudad concentra $97.8 \%$ de la población total de dicha región, cumple la función de ciudad frontera y se localiza a $56 \mathrm{~km}$ de distancia de la urbe de Tacna en Perú. La ciudad chilena más cercana es Iquique, localizada aproximadamente 300 kilómetros al sur. No obstante, Arica se encuentra en una posición central en el continente sudamericano, se constituye en la puerta norte del país, donde la recepción de población migrante a lo largo de su historia ha sido característica.

Arica se emplaza en un territorio esencialmente dinámico donde la presencia de la etnia aimara —entre las más relevantes—es decidora debido a su movilidad tradicional a través de los distintos pisos ecológicos, entre altiplano y costa (Díaz \& Tapia, 2013; González, 2019). En el contexto moderno, la ciudad de Arica nace originalmente bajo el Estado peruano, pero se traspasa a dominio chileno desde 1883, producto de la 
guerra del Pacífico que enfrentó a ambos países, además de Bolivia. Este antecedente no es un mero detalle porque hoy, en términos geopolíticos, la región donde se inserta Arica es una zona de frontera porosa, cuestión que se ve reflejada en sus flujos migratorios y en el carácter central que asume la ciudad por su condición portuaria (Dilla, 2015; González, 2015, 2019).

Desde mediados del siglo $\mathrm{xx}$ hasta la actualidad, las principales dinámicas migratorias se asocian por las fases productivas que la propia ciudad experimentó. La política regional de esos años, relacionada con un proceso de crecimiento "hacia adentro", propició la creación de una zona franca vinculada al puerto y el fomento de la industrialización (Pizarro \& Ríos, 2005; González \& Ovando, 2019). Por lo mismo la ciudad fue atractiva para migrantes de otras regiones del territorio nacional. En aquel periodo, arribaron profesionales y técnicos en cargos estatales, trabajadores de servicios educativos y hospitalarios, y familias desenganchadas de las salitreras, entre otros, para asentarse en una ciudad que transformaba el espacio urbano de su forma tradicional. En paralelo, la dinámica migratoria se identifica por las poblaciones indígenas, principalmente de origen étnico aimara, que provienen del altiplano y de los valles regionales, tales como Putre, Caquena, Codpa, Ticnamar, Azapa y Vitor, entre otras (Meza, 2019; Ovando \& González, 2019).

Desde la década de 1980, la migración aimara produjo un "despoblamiento" de los sectores rurales de la región, debido a que las generaciones jóvenes abandonaron sus hogares de origen motivados por una ciudad que les ofrecía insertarse a las posibilidades de desarrollo moderno (Chipana, 1986). Uno de los antropólogos que estudió a estos pueblos identificó en este proceso las posibilidades concretas de la extinción de la reproducción social de esta cultura, lo que fue definido como "holocausto al progreso" (Van Kessel, 2003).

Interpretaciones contemporáneas indican que el tipo de migración actual, más que un proceso de despoblamiento y de un desplazamiento de origen-destino, se caracteriza por un movimiento circular cuya singularidad fundamental es el flujo entre ciudades, valles y altiplano; fenómeno que trasciende las fronteras estatales debido a que muchas de estas comunidades tienen lazos de parentesco con familias que habitan en Bolivia (Meza, 2019).

Vinculado a la frontera con Perú, el desplazamiento de ida y vuelta hacia la ciudad de Tacna es cotidiano. Los habitantes de Arica viajan a Tacna por servicios turísticos, de alimentación, vestuario y salud. Para la población ariqueña, Tacna ofrece un menor costo de atención sanitaria respecto a Chile. Asimismo, para la población de Tacna, Arica ofrece los servicios de turismo y ocio vinculados al uso de la playa y mercado de consumo especializado. Los desplazamientos entre Arica y Tacna se hacen en buses, taxis colectivos o en tren, este último recientemente renovado para el uso turístico. Esto es lo que autores definen como movilidad transfronteriza en un territorio circulatorio (Tapia et al., 2017; Guizardi \& Valdebenito, 2016; Valdebenito, 2017; Podestá, 2011).

En este marco, las cifras del Servicio Nacional de Aduanas informan de un panorama intenso de movilidad. El registro del paso Chacalluta, ubicado a $12 \mathrm{~km}$ de la ciudad de Arica, acumula más de un tercio del total nacional de tránsito vehicular particular y de pasajeros tanto de entrada como de salida del país, que alcanza los seis millones para 2016 (Tapia et al., 2017).

En este sentido, la dinámica interdependiente con Tacna puede definir a la ciudad de Arica como una metrópolis transfronteriza (Herzog, 1991); sin embargo, esta no 
configura una mancha urbana común, puesto que aún existe una separación amplia en el espacio desértico que dibuja la zona fronteriza de ambos países. Asimismo, entenderla como ciudad gemela (en este caso con Tacna), significa que tengan una similitud e interacción más allá de la frontera (Brites, 2018), cuestión que por ahora resulta incipiente.

Figura 1. Permanencias definitivas entregadas por el Departamento de Extranjería y Migración, región de Arica y Parinacota

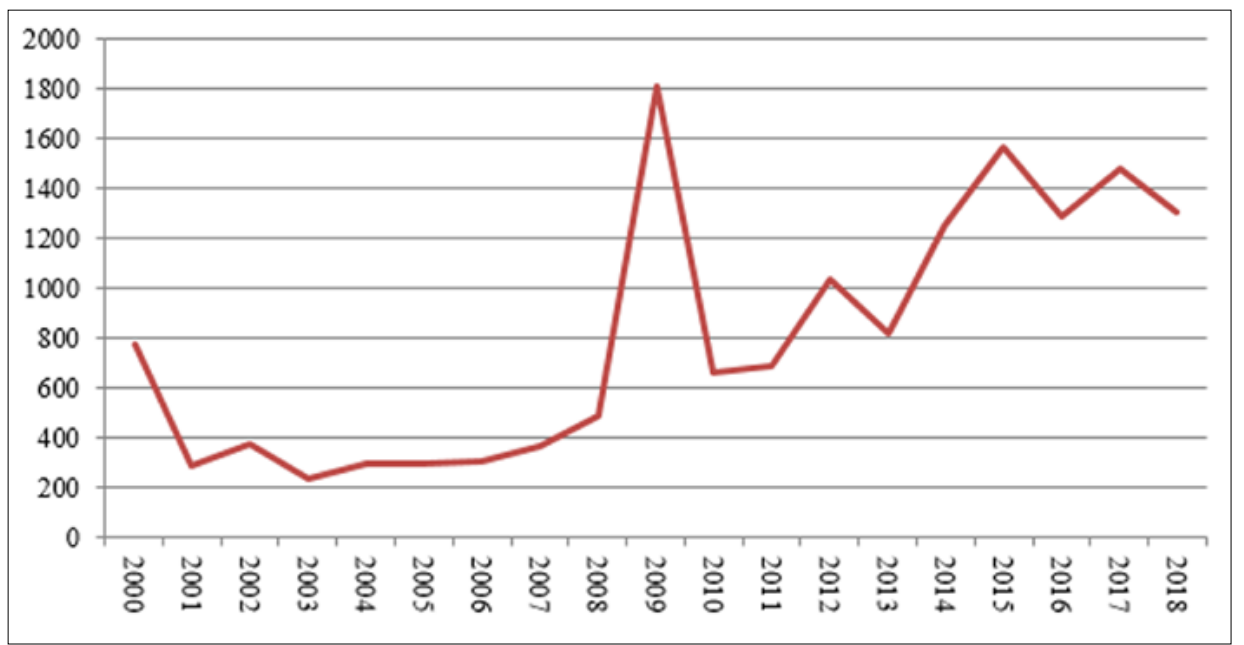

Fuente: Elaboración propia con base en Departamento de Extranjería y Migración, 2019.

Ante estos altos flujos, la cantidad de migrantes extranjeros pueden parecer ínfimos. Sin embargo, su presencia se duplica en la última década solo considerando los registros oficiales del Departamento de Extranjería y Migración del Ministerio del Interior y Seguridad Pública (Figura 1). Este panorama podría verse engrosado si se considera, además, la migración "sin papeles". Según el estudio de Pérez y colaboradores (2015), en la región de Arica y Parinacota se cursaron — solo entre 2011 y 2013- cerca de 5000 sanciones por ejercer función laboral sin disponer de visa. Eso da un panorama mínimo de la movilidad migratoria.

Si se analiza el ingreso al país según nacionalidad de procedencia, de las cerca de 16000 residencias definitivas otorgadas entre 2000 y 2018, Perú y Bolivia concentran $90 \%$, aproximadamente. Siguen con guarismos que no superan 4\%, Colombia $(3.74 \%)$, Venezuela $(1.8 \%)$ y Ecuador $(1.7 \%)$ (Figura 2), números que no hacen más que refrendar el papel de la vecindad que otorga esta ciudad de frontera. Otras características de la población migrante se pueden observar a través del análisis del censo de 2017. En él se aprecia que la población migrante es predominantemente femenina, que la mayoría de las jefaturas de hogar (mujeres u hombres) tiene hasta 12 años de estudio (72\%), 18\% tiene formación técnico profesional y, casi $10 \%$ más de 16 años de escolaridad, es decir, educación universitaria. Ahora bien, más allá de estos datos generales, resulta preponderante indagar cómo se distribuye esta población dentro de la ciudad de Arica, al relacionar su presencia con características generales de habitación en determinadas zonas de la ciudad. 
Figura 2. Ingreso al país según nacionalidad en la región de Arica y Parinacota

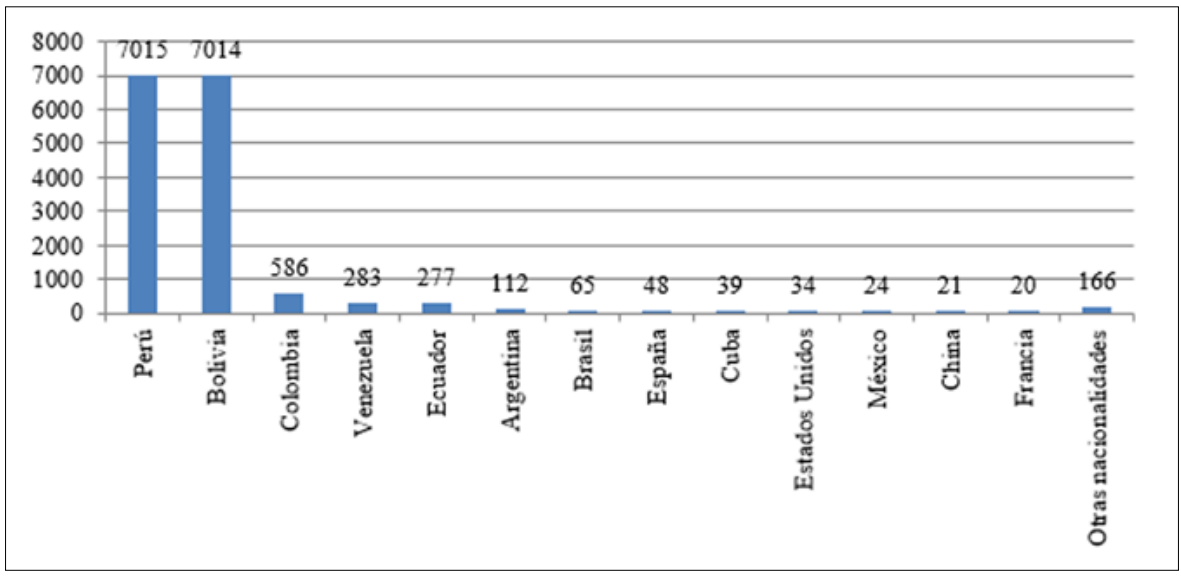

Fuente: Elaboración propia con base en Departamento de Extranjería y Migración, 2019.

\section{La población migrante en la precariópolis ariqueña}

La población migrante tiende a ubicarse en tres grandes áreas de la ciudad de Arica: el norte, el sur y el valle de Azapa. De hecho, tal como se desprende de la Figura 3, prácticamente un tercio de esta población se emplaza en esta última. El resto de la población se distribuye de manera desigual por todas las unidades censales del territorio ariqueño, aunque resaltan los distritos de Pedro Blanquier, Chinchorro, Cancha Rayada, Fuerte Ciudadela, Chaca y Molinos.

Por una parte, llama la atención que la ubicación de estos habitantes se aglutina en el distrito de Azapa, que corresponde a una de las áreas periurbanas de la ciudad en el valle del río San José. Esta es una zona periférica de la ciudad que concentra la actividad agrícola y que en los últimos años ha visto crecer su parque habitacional, sobre todo en relación con un proceso de cambio de residencia de clases altas que llegan a vivir en condominios cerrados o parcelas de agrado.

Pero al mismo tiempo, en ese sector ha continuado la producción agrícola, identificada con el cultivo de olivos y otros frutales, que tradicionalmente han empleado a población proveniente de Perú y Bolivia. Esa población presta labores de servicio doméstico y cuidado de adultos mayores en el resto de la ciudad (Leiva et al., 2017; Stefoni, 2009; Tapia, 2015).

Por su parte, los distritos de Chaca y Molinos poseen un marcado carácter rural. Resulta llamativo que los migrantes tienen un peso determinante sobre la estructura demográfica de los mismos. Si bien la cantidad de habitantes es reducida, estos constituyen la mitad o un tercio, respectivamente. La población de estas zonas - y también en Azapa - habita en viviendas que poseen una condición más precaria, que presentan problemas en el techo, piso o paredes. Sin embargo, no se aprecian condiciones de hacinamiento a diferencia de distritos como Pedro Blanquier, Cancha Rayada o Fuerte Ciudadela (Tabla 2; Figura 3). 
Tabla 2. Sexo y población por distrito. Hacinamiento e índice de calidad de vivienda

\begin{tabular}{|c|c|c|c|c|c|c|c|c|}
\hline Distrito censal & Hombres & Mujeres & Total & $\begin{array}{l}\text { Total de } \\
\text { población } \\
\text { del dis- } \\
\text { trito }\end{array}$ & $\begin{array}{c}\% \\
\text { Población } \\
\text { migrante }\end{array}$ & $\begin{array}{l}\text { Hacinamiento } \\
\text { de la po- } \\
\text { blación mi- } \\
\text { grante }\end{array}$ & $\begin{array}{l}\text { Hacina- } \\
\text { miento } \\
\text { total de la } \\
\text { población }\end{array}$ & $\begin{array}{c}\text { Índice de } \\
\text { calidad } \\
\text { de la } \\
\text { vivienda }\end{array}$ \\
\hline Puerto & 229 & 218 & 447 & 2546 & 17.56 & 1.57 & 3.64 & 0.93 \\
\hline Regimiento & 206 & 256 & 462 & 4454 & 10.37 & 2.87 & 3.36 & 0.96 \\
\hline Chinchorro & 606 & 735 & 1341 & 20728 & 6.47 & 4.89 & 3.16 & 0.98 \\
\hline San José & 233 & 333 & 566 & 11932 & 4.74 & 5.63 & 3.75 & 0.92 \\
\hline Población Chile & 249 & 382 & 631 & 8237 & 7.66 & 3.22 & 4.06 & 0.89 \\
\hline Azapa & 3086 & 3058 & 6144 & 21601 & 28.44 & 0.91 & 3.87 & 0.74 \\
\hline José Manuel Balmaceda & 261 & 374 & 635 & 11000 & 5.77 & 4.43 & 3.91 & 0.93 \\
\hline Carlos Dittborn & 276 & 487 & 763 & 9907 & 7.70 & 3.53 & 3.68 & 0.93 \\
\hline Parque Lauca & 137 & 158 & 295 & 4216 & 7.00 & 3.83 & 3.73 & 0.89 \\
\hline José Miguel Carrera & 128 & 168 & 296 & 5218 & 5.67 & 4.68 & 3.76 & 0.91 \\
\hline Condell & 133 & 197 & 330 & 5506 & 5.99 & 4.74 & 3.52 & 0.95 \\
\hline Fuerte Ciudadela & 550 & 897 & 1447 & 36633 & 3.95 & 6.78 & 3.73 & 0.95 \\
\hline Chaca & 83 & 96 & 179 & 338 & 52.96 & 0.56 & 3.35 & 0.47 \\
\hline El Morro & 173 & 233 & 406 & 3028 & 13.41 & 2.05 & 3.64 & 0.91 \\
\hline Chacalluta & 336 & 297 & 633 & 2966 & 21.34 & 1.42 & 3.30 & 0.76 \\
\hline Molinos & 85 & 71 & 156 & 478 & 32.64 & 1.09 & 2.81 & 0.69 \\
\hline Pedro Blanquier & 707 & 904 & 1611 & 31324 & 5.14 & 5.24 & 3.71 & 0.95 \\
\hline Cancha Rayada & 499 & 742 & 1241 & 27530 & 4.51 & 5.81 & 3.82 & 0.95 \\
\hline Las Torres & 349 & 491 & 840 & 11775 & 7.13 & 3.74 & 3.75 & 0.92 \\
\hline Rezagados & 472 & 251 & 723 & 1947 & 37.13 & 0.19 & 14.32 & 0.87 \\
\hline Total & 8798 & 10348 & 19146 & 221364 & 8.65 & 3.12 & 4.14 & 0.92 \\
\hline
\end{tabular}

Fuente: Elaboración propia con base en Censo de Población y Vivienda (INE, 2017)

Estos tres últimos distritos (Cancha Rayada, Pedro Blanquier y Fuerte Ciudadela) concentran un cuarto del total de la población migrante. Dado que son zonas muy pobladas, la migración no tiene gran peso sobre el total general. Estos barrios se han urbanizado en las últimas décadas mediante la construcción de vivienda subsidiada. Resulta interesante que la población migrante peruana y boliviana se localice en estas zonas, puesto que el acceso formal a la propiedad mediante subsidio requiere cumplir requisitos de permanencia en el país, conformación de núcleos familiares y demostración de situación de vulnerabilidad según el estándar gubernamental. Con esto no se quiere establecer que toda la población migrante logra hacer uso de estos mecanismos, puesto que también pueden llegar a estas zonas mediante arriendo u otro tipo de accesos. Sin embargo, como se aprecia en la Tabla 2, su presencia en términos cuantitativos resulta notable. 
Figura 3. Hacinamiento en Arica

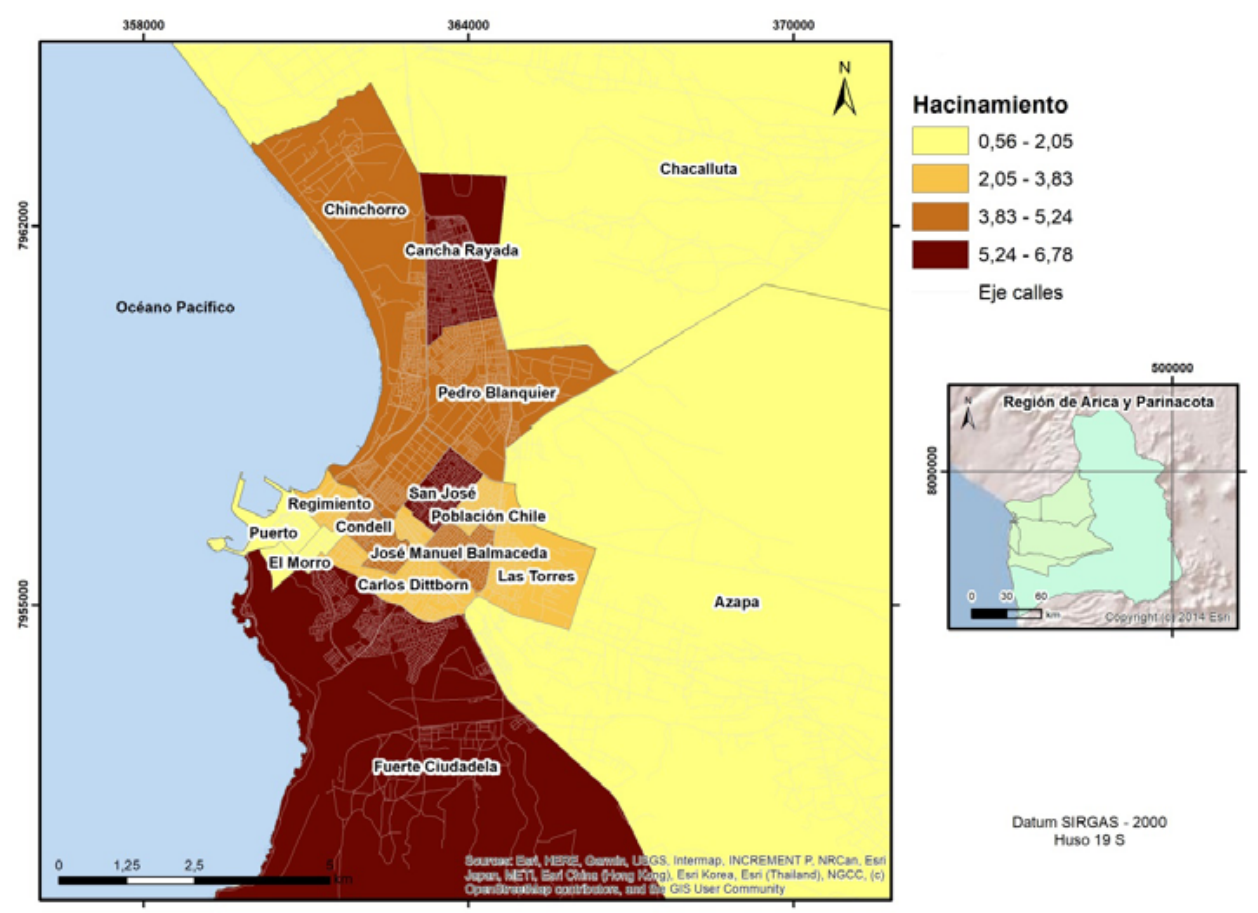

Fuente: Elaboración propia mediante Arc Gis 10.1, con base en Censo de Población y Vivienda (INE, 2017)

Ahora bien, estos espacios de la ciudad están caracterizados por un paisaje donde dominan las edificaciones de casas pareadas y edificios de cuatro pisos, correspondientes a estas viviendas. A ellas se les agregan servicios, comercio u otra infraestructura, tales como talleres mecánicos, negocios de barrio e iglesias. La observación de estos espacios permite apreciar que son lugares mayoritariamente monofuncionales, donde predominan los usos habitacionales en desmedro de otros (Figura 4).

La accesibilidad resultaba dificultosa desde el centro de la ciudad o desde las áreas urbanizadas durante la época desarrollista (décadas de 1960 y 1970). La trama urbana se encuentra relativamente fragmentada, ya sea por autopistas que la segmentan o bien por la presencia de altitud, como es la zona sur. Sin embargo, lo que parece más relevante es la fragmentación a escala barrial, ya sea porque las nuevas tipologías de la vivienda subsidiada se efectúan bajo la lógica de barrios cerrados o bien porque algunas vecindades deliberan y cierran sus pasajes por diferentes motivos, lo que corta el tránsito peatonal.

Estas características resultan propias de las precariópolis estatales descritas por Hidalgo $(2007,2018)$. Urbanizaciones creadas bajo el modelo de vivienda subsidiada, ubicadas en los nuevos márgenes extendidos de la ciudad, caracterizadas por problemas internos del hogar como el hacinamiento, o por estar relativamente fragmentados de los espacios urbanos centrales y generalmente contiguos a zonas de riesgo ambiental. La zona norte de Arica resulta paradigmática por la presencia de residuos de polimetales y la construcción de dos poblaciones contiguas a este lugar: Los Industriales y Cerro Chuño. Esta última ha sido objeto de una larga disputa. 
Figura 4. Arica Norte

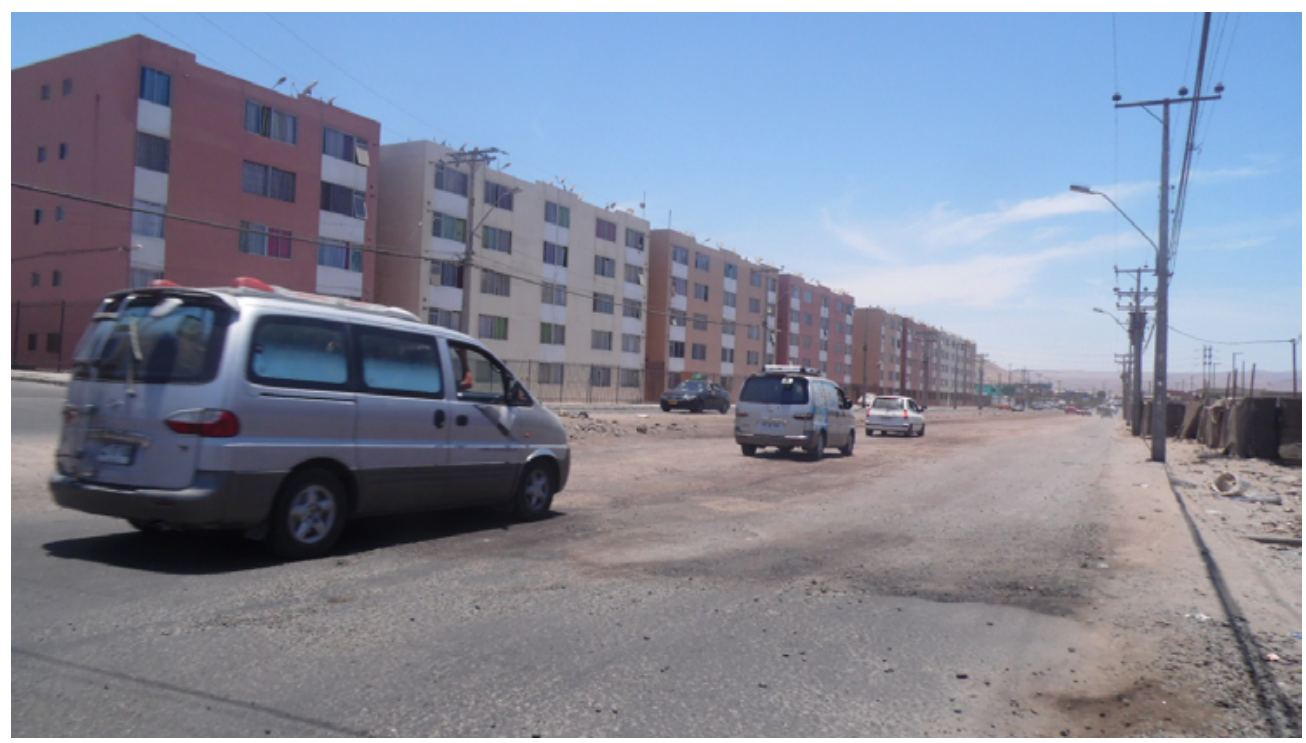

Fuente: Elaboración propia

\section{¿Hacia la conformación de un gueto migrante en Cerro Chuño?}

La población Cerro Chuño es un espacio producido por la política de vivienda subsidiada del Estado de Chile. Su construcción comenzó a inicios de la década de 1990 sobre un terreno usado como vertedero dentro de una antigua zona de uso industrial, ubicada en la periferia nororiente de Arica. A finales de la década de 1980, se importaron más de veinte mil toneladas de residuos tóxicos de la empresa sueca Boliden, los cuales fueron depositados en el Sitio F de propiedad estatal (Valdebenito \& Navarro, 2019).

Los registros de la época muestran a niños y niñas que jugaban con el "barro", lo llevaban a sus casas y lo esparcían por todos los lugares por donde transitaban (Colectivo Salud en Movimiento, 2019). El problema es que el barro contenía plomo y arsénico que quedaba expuesto a la población. El nulo resguardo de los desechos significó que estos materiales se esparcieran por la zona norte de la ciudad de Arica, que la contaminó y produjo enfermedades en centenares de personas (Instituto Nacional de Derechos Humanos, 2012).

La gravedad de la problemática se acrecentó en la década de 1990, cuando el Servicio de Vivienda y Urbanismo de Arica decide la producción de aproximadamente 12000 viviendas en la zona contigua a los desechos, donde se construyeron los conjuntos habitacionales Los Industriales y Cerro Chuño. A finales de la década de 1990 se realizó una serie de denuncias por problemas de salud que afectaron a la población expuesta a los polimetales.

Tras investigaciones científicas y las visitas de las autoridades (Saavedra, 2019; Colectivo Salud en Movimiento, 2019), a finales de 2009 se tomaría la determinación, a través del Plan Maestro del Caso Polimetales de Arica, de erradicar y demoler la 
totalidad de la población de Cerro Chuño y una parte de Los Industriales. Sin embargo, esta acción no terminó de concretarse. Si bien la población fue erradicada, no toda la gente que habitaba este lugar fue beneficiaria de una relocalización digna, cuestión que tuvo como consecuencia que algunas de las casas fuesen tomadas nuevamente.

En la actualidad, Cerro Chuño es una población que exhibe el fracaso de las políticas de vivienda subsidiada en Chile. Su paisaje es el de un espacio en ruinas a medio destruir (Figura 5). Hay abundancia de escombros y basura por todas partes. Una parte de las viviendas fue demolida, pero otras hacia el interior persisten en su estructura inicial, las que han sido arregladas con puertas, ventanas e incluso ampliaciones. Estas poseen acceso irregular al alcantarillado y agua potable, y la mayoría se encuentra con acceso informal a la electricidad. De todos modos, no es un barrio desolado. Se hace uso de la calle por sus habitantes y se observa la presencia de comercio (talleres de autos, botillerías, abarrotes, comercio ambulante).

Estas actividades se desarrollan en medio de la aridez de la ciudad que hace aumentar la intensidad de sus aromas y formas que estructuran el paisaje de Cerro Chuño: aceite quemado, bencina, basura quemada, humo de tubos de escape, fritura y comida rápida. Hacia el límite este del conjunto habitacional se observan residuos de todo tipo, que se combinan con nuevas viviendas precarias y chatarra automovilística. En este marco, pareciese que la vida no tiene condiciones para reproducirse. Aun así, buena parte de la población lo hace. Existe una relación de dependencia respecto al camión aljibe, el cual reparte agua potable, y a comerciantes particulares que venden bidones de agua.

\section{Figura 5. Cerro Chuño}

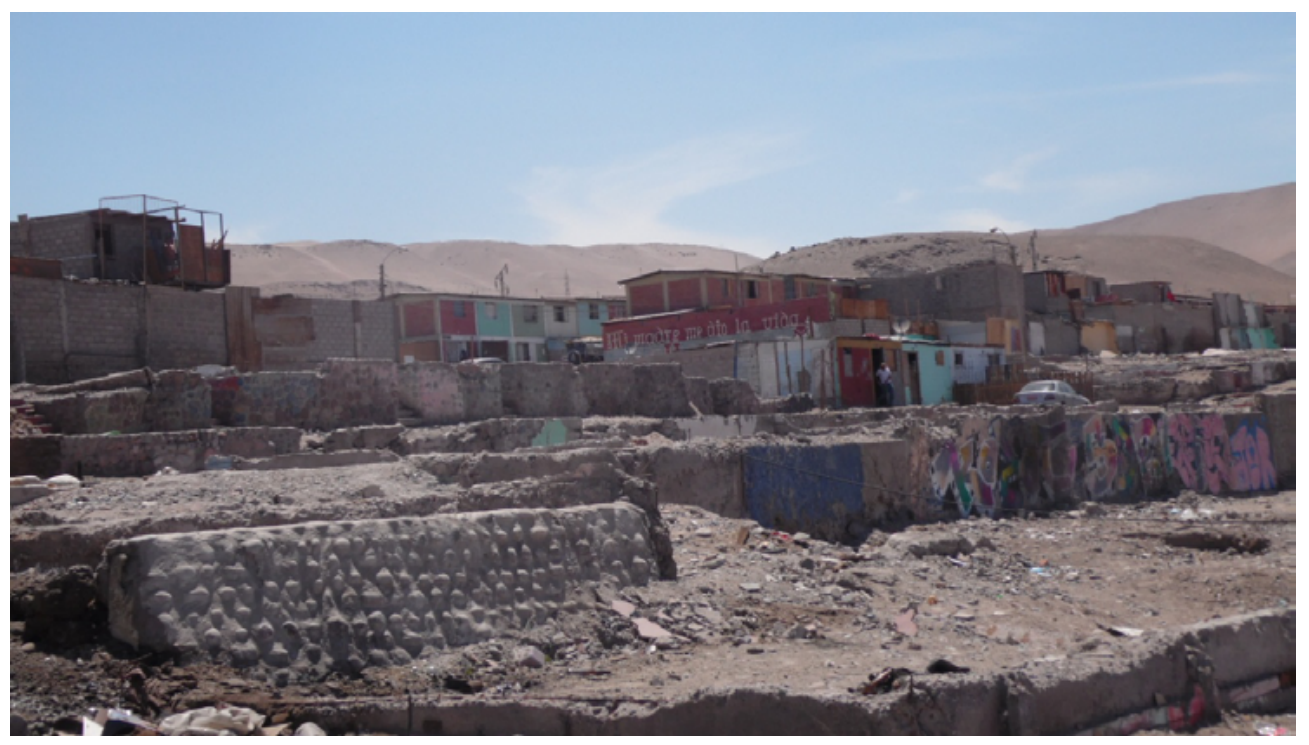

Fuente: Elaboración propia

Para los habitantes de Arica, este lugar se ha convertido progresivamente en tierra de nadie. La avenida Capitán Ávalos, vía de acceso principal a esta población, se ha transformado en una frontera urbana. Ingresar a Cerro Chuño significa adentrarse en un mundo donde rige una norma propia, donde habitar implica adecuarse a una forma 
de vivir que debe asumir un riesgo sanitario-vital permanente; estar sujeto a la presión estatal de la erradicación sin solución habitacional; o convivir con esporádicas bandas de narcotraficantes que ocupan viviendas abandonadas (Saavedra, 2019). Tal como Santos (1990) expuso hace largo tiempo, el paisaje es un producto social apreciable a través de las rugosidades que, no solo expresan el paso del tiempo histórico, se erigen como herencias del pasado que las sociedades asumen y testimonios de una época.

Actualmente en Cerro Chuño aún habitan más de mil personas con residencia estable. De acuerdo con los últimos catastros oficiales, la composición de su población según origen nacional indica que la mitad de la población es chilena, mientras que el resto son personas provenientes de Colombia, Perú, Bolivia, República Dominicana, Venezuela y Haití (Ministerio de Vivienda y Urbanismo, 2018; El Morrocotudo, 2018).

Este asentamiento tiene un notable carácter migrante. Es apreciable a simple vista con solo transitar por él. Sin embargo, la población migrante que llega ahí no tiende a permanecer por largo tiempo. Su permanencia es transitoria y volátil. Depende de las posibilidades otorgadas por las redes familiares, oportunidades laborales o formalización de su estancia en el país. Valdebenito y Navarro (2019) señalan que un rasgo común de las familias que pasan por Cerro Chuño es que tienen trayectorias vitales cruzadas por estar sujetas a contextos de violencia política y/o sexual de los lugares de procedencia, por encontrarse en un tránsito incesante entre varios lugares del subcontinente, o por la ausencia de documentación regularizada en su ingreso a Chile. En este sentido, este lugar ha adquirido más bien las características de un asentamiento móvil. La migración, entonces, no se produce bajo una lógica origen/destino prefijado, sino que más bien es la movilidad de una masa de fuerza de trabajo que está en la búsqueda de poder asentarse, aunque esa finalidad sea indeterminada (Salazar, 2019).

Cerro Chuño muestra una doble condición. Por un lado, persiste la presencia histórica de algunas familias que esperan mitigaciones o compensaciones debido a la negligencia estatal y, por otro, es un asentamiento transitorio que, dada su condición de ruina de la política de vivienda subsidiada chilena, permite una serie de oportunidades que desbordan al marco jurídico vigente: precios de habitaciones más baratas, mantenerse ocultos bajo condición de irregularidad o desarrollar actividades ilícitas.

El tratamiento gubernamental a esta problemática ha desarrollado un estigma sobre Cerro Chuño. La prensa ha tendido a caracterizarlo como un espacio de criminalidad y las agencias regionales de gobierno operan cautelosamente bajo preceptos xenófobos y racistas (Autoridades buscan evitar que Cerro Chuño se convierta en "tierra de nadie", 2020). Sin lugar a duda, este contexto expone a sus habitantes a los mecanismos punitivos del Estado y, por consecuencia, al no reconocimiento público (Sassen, 2016b). Tal como establece Wacquant (2010), el estigma se basa en imponer una identidad manchada desde aparatos institucionales, lo que es amplificado por las redes de medios de comunicación.

La acción del Estado, a través de la Secretaría Regional Ministerial de Vivienda y Urbanismo, permite pensar en la aplicación de dispositivos de confinamiento espacial propios de un gueto. Una de las formas de solucionar el conflicto particular de la vivienda ha sido a través de la asignación de subsidios y la posterior relocalización de la población. Sin embargo, los subsidios no alcanzan para toda la población involucrada, y más bien han sido usados como dispositivo de control y separación.

Ahora bien, a pesar del grado de confinamiento espacial existente y del estigma, no puede demostrarse la presencia de una pluralidad de clases sociales dentro de Cerro Chuño, cuestión que impediría hablar de un gueto según la definición de Wacquant (2010). Más 
bien allí se encuentra la población que no ha podido huir de ahí, están de tránsito y se vuelcan al trabajo informal como estrategia de sobrevivencia, cuestión que habla de la degradación de los mecanismos de integración social y, en definitiva, de la estructuración de condiciones de marginalidad urbana avanzada (Wacquant, 2001).

$\mathrm{Si}$ bien no todas las áreas pobres ni todas las áreas segregadas implican la constitución de un gueto (Wacquant, 2010), las dinámicas mercantiles de la población tensionan esta condición. La proliferación de un mercado informal de arriendo y de compraventa de viviendas controlado por grupos de personas que han impuesto algunas exigencias en el acceso a la vivienda tomada (Valdebenito \& Navarro, 2019) puede ser considerado como una forma de enclaustramiento organizativo o de duplicidad de instituciones.

De todas formas, a diferencia de las visiones mecanicistas, que podrían sugerir que todos los males se posan sobre Cerro Chuño, para generar interpretaciones cerradas en torno a la idea de gueto por su fácil aplicación a un contexto crítico como este, no resulta tan claro el deterioro del entramado social. De hecho, la articulación política entre pobladores y organismos no gubernamentales ha sido factor para frenar desalojos propuestos por la autoridad ministerial (Valdebenito \& Navarro, 2019). En este sentido, la acción organizada ha logrado detener los embates de la institucionalidad, la que a pesar de desarrollar un plan maestro de intervención hace más de 10 años, no ha logrado generar establecer una línea de trabajo que signifique un mejoramiento sustantivo de las condiciones vitales de la población involucrada.

\section{A modo de cierre}

La ciudad fronteriza de Arica se constituye como una puerta de ingreso a Chile. Sin embargo, el flujo migratorio se dirige principalmente hacia otras ciudades del norte y centro del país. La detención en la ciudad de Arica permite conseguir trabajos temporales en agricultura, comercio, construcción o turismo y, también, moverse a las ciudades de los países limítrofes.

En términos generales, la presencia migrante en Arica se ha duplicado desde 2010 a la fecha, donde destacan las poblaciones peruana y boliviana, que constituyen $90 \%$ del total. Estas han tenido una presencia tradicional en el territorio debido a la movilidad ancestral y a las funciones de Arica, entendida como un espacio litoral, costero y portuario de la región andina, cuestión que se ha dinamizado en el siglo Xxi a propósito de la búsqueda de oportunidades laborales. Si bien se expresa una importante movilidad y migración, Arica tiene características internas definidas por el modelo político chileno que difiere de los conceptos de metrópolis transfronterizas o de ciudades gemelas, cuestión que podría definirse solo por la dinámica adquirida con Tacna. En este sentido, la frontera demarca y regula el espacio y a los sujetos que ingresan según mecanismos binarios definidos en torno a lo formal/informal.

Por otra parte, nuevos sujetos destacan como expresión de un nuevo tipo de migración que se genera por los corredores continentales que conectan a Chile con el continente. En este sentido, la atracción hacia Chile se produce más bien por la imagen de progreso y prosperidad que se ha construido y exportado durante décadas de crecimiento económico, lo que promueve una representación que detona la movilidad de estos grupos. Dentro de la masa migrante, un grupo solo puede acceder a asentarse en ambientes predominantemente precarios, ya sea por la deficiente calidad 
de la vivienda o por condiciones de habitabilidad que distan de lo óptimo y lo digno: Cerro Chuño es la expresión más notable de aquello.

En esta zona, caracterizada por un conflicto ambiental de larga data, casi $50 \%$ de la población es migrante. Si bien esta zona presenta confinamiento habitacional, duplicidad de instituciones expresada en la creación de mercados informales de arriendo y compraventa de vivienda y un fuerte estigma público posado sobre ella, no resulta del todo factible aplicar la categoría de gueto (Wacquant, 2010), puesto que también hay condiciones de marginalidad avanzada atribuibles a la categoría de hipergueto (Wacquant, 2001), caracterizado por una mayor violencia, degradación y precariedad.

Cerro Chuño se constituye como un espacio residencial móvil donde, a pesar del estigma público que pesa sobre la zona y quienes la habitan, también se establecen redes de solidaridad, trabajo con organizaciones sociales y resguardo de sus habitantes. Esta población es quizás uno de los ejemplos más graves y elocuentes del modo de producción de espacio residencial precario del Estado neoliberal chileno: la ejecución de la política de vivienda subsidiada en medio de una "zona de sacrificio" ambiental, con varios cientos de personas enfermas y otras fallecidas a cuestas. Sin lugar a duda, una expresión mucho más real respecto a las posibilidades e imágenes proyectadas internacionalmente por Chile.

\section{Agradecimientos}

Este artículo contó con el financiamiento del proyecto Fondecyt Regular 1191555 "La producción de vivienda subsidiada en ciudades fluviales, marinas y lacustres en Chile: integración y sostenibilidad 2000-2017".

\section{Referencias}

Alarcón, R. (2019). Solicitantes de asilo a Estados Unidos a la espera en ciudades fronterizas mexicanas. Anuario СІDов de la Inmigración 2019 (pp. 98-111). https:/ / doi. org/10.24241/AnuarioCIDOBInmi.2019.98

Alegría, T. (2009). Metrópolis transfronteriza. Revisión de la hipótesis y evidencias de Tijuana, México y San Diego, Estados Unidos. El Colef/M. A. Porrúa.

Autoridades buscan evitar que Cerro Chuño se convierta en "tierra de nadie". (2020, 27 de septiembre). Arica al día. https://www.aricaldia.cl/autoridades-buscan-evitar-que-cerro-chuno-se-convierta-en-tierra-de-nadie/

Bourdieu, P., Chambordeon, J. C. \& Passeron, J. C. (2000). El oficio del sociólogo. Siglo XXI Editores.

Brites, W. F. (2018). ¿Ciudades gemelas? Posadas, Argentina, Encarnación, Paraguay en perspectiva sociourbana. Estudios Fronterizos, 19(e020). https://doi. org/10.21670/ref.1820020

Brites, W. F. \& Catullo, M. R. (2016). Represas y transformación socio-urbana. Un análisis comparativo de los proyectos hidroeléctricos de Salto Grande y Yacyretá. Cidades, Comunidades e Territórios, (33), 50-67. http://dx.doi.org/10.15847/citiescommunitiesterritories.dec2016.033.art0 
Butler, J. (2006). Vida precaria. El poder del duelo y la violencia. Paidós.

Canales, A., Fuentes J. A. \& de León, C. R. (2019). Desarrollo y migración: desafíos y oportunidades en los paises del norte de Centroamérica. Comisión Económica para América Latina y el Caribe. https://www.cepal.org/es/publicaciones/44649-desarrollo-migracion-desafios-oportunidades-paises-norte-centroamerica

Carlos, A. F. A. (2007). O lugar no/do mundo. FFLCH. http://gesp.fflch.usp.br/sites/ gesp.fflch.usp.br/files/O_lugar_no_do_mundo.pdf

Chipana, C. (1986). La identidad étnica de los aymarás en Arica. Revista Chungará, (1617), 251-261. http://www.chungara.cl/Vols/1986/Vol1617/La_identidad_etnica_de_los_Aymaras_en_Arica.pdf

Colectivo Salud en Movimiento. (2019). 35 años muriendo: el silencio sobre la contaminación por polimetales en Arica [Video]. YouTube. https://www.youtube.com/ watch? $\mathrm{v}=$ Seh3nZwcPIU\&t $=3 \mathrm{~s}$

Cordero, B., Mezzadra, S. \& Varela, A. (2019). América Latina en movimiento. Migraciones, límites a la movilidad y sus desbordamientos. Universidad Autónoma de la Ciudad de México/Traficantes de sueños.

Coubès, M. L., Velasco, L. \& Contreras, O. (2020). Migrantes en albergues en las ciudades fronterizas del norte de México (Documentos de contingencia 2. Poblaciones vulnerables ante COVID-19). El Colegio de la Frontera Norte. https://www. colef.mx/estudiosdeelcolef/migrantes-en-albergues-en-las-ciudades-fronterizas-del-norte-de-mexico/

Dammert, M. \& Bensús, V. (2017). Border cities and urban expansion: the case of Zarumilla and Aguas Verdes on the Perú-Ecuador Border. Frontera Norte, 29(57), 5-30. http://www.scielo.org.mx/pdf/fn/v29n57/0187-7372-fn-29-57-00005.pdf

Delfino, A. (2012). La noción de marginalidad en la teoría social latinoamericana: surgimiento y actualidad. Universitas Humanística, 74, 17-34. http://www.scielo. org.co/pdf/unih/n74/n74a02.pdf

Departamento de Extranjería y Migración. (2019). Estadísticas migratorias. Registros administrativos del Departamento de Extranjería y Migración. https:/ / www.extranjeria. gob.cl/estadisticas-migratorias/

Díaz, A. \& Tapia, M. (2013). Los aymaras del norte de Chile entre los siglos xix y xx: un recuento histórico. Atenea, (507), 181-196. http://dx.doi.org/10.4067/ S0718-04622013000100012

Dilla, H. (2015). Los complejos urbanos transfronterizos en América Latina. Estudios Fronterizos, 16(31), 15-38. https://doi.org/10.21670/ref.2015.31.a01

Dorfman, A. (2015). Contrabando: pasar es la respuesta a la existencia de una frontera, burlar es el acto asimétrico al control. Aldea Mundo, 20(39), 33-44. https:// www.redalyc.org/pdf/543/54343963004.pdf

Ehlers, N., Buursink, J. \& Boekema, F. (2001). Introduction: Binational cities and their regions: from diverging cases to a common research agenda. GeoJournal, 54(1), 1-5. https://www.jstor.org/stable/41147632?seq=1

El Morrocotudo. (2018, 15 de junio). Extranjeros no encabezan lista: catastro revela las 8 nacionalidades que conviven en Cerro Chuño. https://www.elmorrocotudo. $\mathrm{cl} /$ noticia/sociedad/extranjeros-no-encabezan-lista-catastro-revela-las-8-nacionalidades-que-conviven-en 
Enríquez, J. (2007). Entre el miedo y la distinción. El estado actual del fraccionamiento cerrado en las ciudades fronterizas de Tijuana, Nogales y Ciudad de Juárez. Estudios Fronterizos, 8(15), 9-49. https://doi.org/10.21670/ref.2007.15.a01

Espín, J. (2013). La problemática de la violencia y el respeto a la vida en la frontera norte. En F. Carrión, D. Mejía \& J. Espín (Comps.), Aproximaciones a la frontera (pp. 37-50). Flacso Ecuador. http://biblioteca.clacso.edu.ar/Ecuador/flacso-ec/20170622042509/pdf_122.pdf

Fernández Niño, J. A., Vásquez-Rodríguez, A. B., Flórez-García, V. A., Rojas-Botero, M. L., Luna-Orozco, K., Navarro-Lechuga, E., Acosta-Reyes, J. L. \& Rodríguez Pérez, D. A. (2018). Modos de vida y estado de salud de migrantes en un asentamiento de Barranquilla, 2018. Salud Pública, 20(4), 530-538. https://scielosp. org/pdf/rsap/2018.v20n4/530-538/es

González, S. (2015). La voz desde lejos. La triple-frontera andina: entre la heterología y la globalización. Andamios, 12(28), 19-41. http://www.scielo.org.mx/pdf/ anda/v12n28/1870-0063-anda-12-28-00019.pdf

González, S. (2019). La frontera como margen heterológico. El tripartito andino (Bolivia, Perú y Chile) y el espejismo académico sobre los "aymaras sin fronteras". Diálogo Andino, (60), 115-125. http://dialogoandino.cl/wp-content/uploads/2019/12/09-GONZALEZ-MIRANDA-RDA60.pdf

González, S. \& Ovando, C. (2010). La provincia de Arica y la Región xv Arica-Parinacota entre la descentralización y la historia (1884-2007). Si Somos Americanos. Revista de Estudios Transfronterizos, 10(1), 59-79. https://www.sisomosamericanos. $\mathrm{cl} /$ index.php/sisomosamericanos/article/view/27

González, S. \& Ovando, C. (2019). La 'cuestión regional' y la 'cuestión indígena' en el desarrollo histórico de Arica, Chile (1929-1974). Interciencia, 45(1), 42-48. https://www.interciencia.net/wp-content/uploads/2020/02/42_6591_E_Gonzalez_Miranda_v45n1.pdf

Guasch, O. (1996). Observación participante. Centro de Investigaciones Sociológicas.

Guizardi, M. \& Valdebenito, F. (2016). El (des)control de las fronteras: la migración peruana en Arica-Chile tres dinámicas trasnacionales. Revista Chilena de Antropología, (33), 103-119. https://revistadeantropologia.uchile.cl/index.php/ $\mathrm{RCA} /$ article/view/43393

Herzog, L. (1991). International boundary cities: the debate on transfrontier planning in two border regions. Natural Resources Journal, 31(3), 587-608. https://www. jstor.org/stable/24883668?seq=1

Hidalgo, R. (2007). ¿Se acabó el suelo en la gran ciudad? Las nuevas periferias metropolitanas de la vivienda social en Santiago de Chile. EURE (Santiago), 33(98), 57-75. http://dx.doi.org/10.4067/S0250-71612007000100004

Hidalgo, R. (2018). La dispersión de la vivienda social en gran escala en la periferia metropolitana de Santiago de Chile. La precariópolis y el derecho a la ciudad. En D. Soldano, A. Novick, M. C. Cravino \& A. Barsky. (Comps.), Pobreza urbana, vivienda y segregación residencial en América Latina (pp. 111-127). Ediciones UNGS/ Universidad Nacional de General Sarmiento. https://www.researchgate.net/ publication/329739254_La_dispersion_de_la_vivienda_social_en_gran_escala_en_la_periferia_metropolitana_de_Santiago_de_Chile_La_precariopolis_y_ el_derecho_a_la_ciudad 
Hiernaux, D. (1994). La problemática de las ciudades fronterizas. En A. Encinas \& E. Anaya (Eds.), Frontera Norte (pp. 105-111). H. Cámara de Diputados-LV Legislatura-Comisión Asentamientos Humanos-Obras Públicas. https://www. researchgate.net/profile/Daniel-Hiernaux/publication/299583599_La_problematica_de_las_ciudades_fronterizas/links/5700a5c308ae1408e15df67a/ La-problematica-de-las-ciudades-fronterizas.pdf

Instituto Nacional de Derechos Humanos. (2012). Mapa de conflictos socioambientales en Chile. https://mapaconflictos.indh.cl/\#/

Instituto Nacional de Estadísticas (INE). (2017). Censo de Población y Vivienda 2017. https://www.ine.cl/estadisticas/sociales/censos-de-poblacion-y-vivienda/poblacion-y-vivienda

Instituto Nacional de Estadísticas (INE) \& Departamento de Extranjería y Migración (DEM). (2020). Estimación de personas extranjeras residentes en Chile al 31 de diciembre de 2019. https://www.ine.cl/docs/default-source/demografia-y-migracion/publicaciones-y-anuarios/migraci\%C3\%B3n-internacional/estimaci\%C3\%B3n-poblaci\%C3\%B3n-extranjera-en-chile-2018/ estimaci\%C3\%B3n-poblaci\%C3\%B3n-extranjera-en-chile-2019-metodolog\%C3\%ADa.pdf?sfvrsn=5b145256_6

Jiménez, E. (2017). Inmigrantes haitianos en la población Los Nogales de la comuna de Estación Central. Segregación residencial y proceso de guetización (Tesis de maestría). Facultad de Ciencias Sociales, Universidad de Chile.

Leiva, S., Mansilla, M. \& Comelin, A. (2017). Condiciones laborales de migrantes bolivianas que realizan trabajo de cuidado en Iquique. Si Somos Americanos. Revista De Estudios Transfronterizos, 17(1), 11-37. http://dx.doi.org/10.4067/S071909482017000100011

Lorey, I. (2016). Estado de inseguridad. Gobernar la precariedad. Traficantes de Sueños.

Martínez Pizarro, J. (2000). La migración internacional y el desarrollo en la era de la globalización e integración: temas para una agenda regional. Cepal. https://www.cepal. org/sites/default/files/publication/files/7128/S2000942_es.pdf

Méndez, E., Rodríguez, I. \& López, L. (2005). El modelo actual de ciudad fronteriza mexicana. Urbanismos yuxtapuestos y herméticos. Bifurcaciones: Revista de estudios culturales urbanos, (4), 1-14. http://www.bifurcaciones.cl/004/bifurcaciones_004_MRL.pdf

Mendoza, C. (2014). ¿Ciudad de paso o destino migratorio? El papel de las ciudades de la frontera norte de México en la construcción de circuitos migratorios México-Estados Unidos. En M. Tapia \& A. González (Coords.), Regiones fronterizas. Migración y los desafíos para los Estados nacionales latinoamericanos (pp.177-200). RIL Editores.

Meza, M. (2019). Cuencas transfronterizas y áreas de montaña. Enfoques y perspectivas desde el campo del saber geográfico. Interciencia, 44(12), 698-706. https://www. interciencia.net/wp-content/uploads/2020/01/05_698_Com_Meza_v44n12.pdf

Ministerio de Vivienda y Urbanismo. (2018). Informe de ocupación Cerro Chuño. Arica: Servicio de Vivienda y Urbanismo.

Módenes, J. (2008). Movilidad espacial, habitantes y lugares: retos conceptuales y metodológicos para la geodemografía. Estudios Geográficos, 69(264), 157-178. https://doi.org/10.3989/egeogr.2008.i264.83 
Mora, C. (2009). Estratificación social y migración interregional: algunas caracterizaciones de la experiencia migratoria latinoamericana. Universum (Talca), 24(1), 128-143. http://dx.doi.org/10.4067/S0718-23762009000100008

Moreno-Izquierdo, L. \& Lucero, A. (2010). La persistencia de los guetos en América Latina y el Caribe comportamiento de las posibles variables explicativas. En: M. Sevilla, T. Torregrosa (Coords.), Anales de economía aplicada (núm. 24). Delta publicaciones/Asepelt, Asociación Internacional de Economía Aplicada http:// www.asepelt.org/ficheros/File/Anales/2010-Alicante/ANALES-ECONOMIA-APLICADA-2010.pdf

Muñoz Jumilla, A. R. (2002). Efectos de la globalización en las migraciones internacionales. Papeles de Población, 8(33), 9-45. http://www.scielo.org.mx/pdf/pp/ v8n33/v8n33a2.pdf

Ovando, C. \& González, S. (2019). Imaginarios geopolíticos en torno al desarrollo regional de Arica y Parinacota (1960-2014). Interciencia, 44(12), 668-675. https://www.interciencia.net/wpcontent/uploads/2020/01/01_668_A_Ovando_v44n12.pdf

Pellicer, I., Vivas-Elías, P. \& Rojas, J. (2013). La observación participante y la deriva: dos técnicas móviles para el análisis de la ciudad contemporánea. El caso de Barcelona. EURE (Santiago), 39(116), 119-139. http://dx.doi.org/10.4067/S025071612013000100005

Peña, L. (2015). Abandono de vivienda, violencia y deterioro urbano, panorama de las ciudades fronterizas con Estados Unidos. Ciudad Juárez, Chihuahua, México. En A. Sehtman \& E. Zenteno (Coords.), Continuidades, rupturas y emergencias. Las desigualdades urbanas en la América Latina (pp. 175-188). PUEC/UnAm. https:// www.researchgate.net/publication/295449053_Abandono_de_vivienda_violencia_y_deterioro_urbano_panorama_de_las_ciudades_fronterizas_con_Estados_Unidos_Ciudad_Juarez_Chihuahua_Mexico

Pérez, C., Lube, M., Vicuña, J. \& Rojas, T. (2015). Del contexto fronterizo y migratorio. En J. T. Vicuña \& T. E. Rojas (Eds), Migración en Arica y Parinacota: Panoramas y tendencias de una región fronteriza (49-70). Orden Religiosa Compañía de Jesús-Servicio Jesuita a Migrantes. https://bibliotecadigital.indh.cl/ bitstream/handle/123456789/911/Migraci\%F3n\%20en\%20Arica\%20y\%20 Parinacota.pdf?sequence $=1$

Pizarro, E. \& Ríos, W. (2005). Entre franquicias y beneficios: una apuesta del gobierno para el desarrollo regional de Arica (1953). Diálogo Andino, (25), 101-111. http://dialogoandino.cl/wp-content/uploads/2016/07/DA-25-2005-06.pdf

Podestá, J. (2011). Regiones fronterizas y flujos culturales: la peruanidad en una región chilena. Universum (Talca), 26(1). 123-137. http://dx.doi.org/10.4067/ S0718-23762011000100008

Rodríguez, J. \& Espinoza, D. (2012). Recuperación del atractivo migratorio metropolitano en el periodo 2004-2009: ¿factores exógenos o endógenos? Revista de geografía Norte Grande, (51), 95-113. https://dx.doi.org/10.4067/S071834022012000100006

Saavedra, M. (2019). Análisis de los factores sociales y de contaminación actuales que propician los escenarios de riesgo crónico para el sector Cerro Chuño, ciudad de Arica, Región de Arica y Parinacota (Tesis de grado). Facultad de Arquitectura y Urbanismo, Universidad de Chile. http://repositorio.uchile.cl/handle/2250/173651 
Sabatini, F. \& Brain, I. (2008). La segregación, los guetos y la integración social urbana: mitos y claves. EURE (Santiago), 34(103), 5-26. https://scielo.conicyt.cl/ scielo.php?script=sci_arttext\&pid=S0250-71612008000300001

Salazar, N. (2019). Mobility. RемHU: Revista Interdisciplinar da Mobilidade Humana, 27(57), 13-24. https://doi.org/10.1590/1980-85852503880005702

Santos, M. (1990). Por una geografía nueva. Espasa Calpe.

Saraví, G. (2020). Acumulación de desventajas en América Latina: aportes y desafíos para el estudio de la desigualdad. RELAP Revista Latinoamericana de Población, 14(27), 228-256. https://doi.org/10.31406/relap2020.v14.i12.n27.7

Sassen, S. (2003). Contrageografías de la globalización. Género y ciudadania en los circuitos transfronterizos. Traficantes de Sueños.

Sassen, S. (2016a). Expulsions: Brutality and Complexity in the Global Economy. Harvard University Press.

Sassen, S. (2016b). A massive loss of habitat: new drivers for migration. Sociology of Development, 2(2), 204-233. https://doi.org/10.1525/sod.2016.2.2.204

Schiappacasse, P. (2008). Segregación residencial y nichos étnicos de los inmigrantes internacionales en el área metropolitana de Santiago. Revista de Geografia Norte Grande, (39), 21-38. http://dx.doi.org/10.4067/S0718-34022008000100003

Sohn, C. (2014). The border as resource in the global urban space: a contribution to the cross-border metropolis hypothesis. International Journal of Urban and Regional Research, 38(5), 1697-1711. https://doi.org/10.1111/1468-2427.12071

Souza, E. \& Brites, W. (2017). Dinámicas urbanas en ciudades gemelas impactadas por hidroeléctricas. Terra Plural, 11(2), 271-290. https://doi.org/10.5212/TerraPlural.v.11i2.0007

Stefoni, C. (2009). Migración, género y servicio doméstico. Mujeres peruanas en Chile. En M. Valenzuela \& C. Mora (Eds.), Trabajo doméstico. Un largo camino hacia el trabajo decente (pp. 191-232). OIT. http://www.ilo.org/wcmsp5/groups/public/-americas/-ro-lima/-sro-santiago/documents/publication/wcms_180549.pdf

Steiman, R. (2012). Zona de fronteira e cidades gêmeas: Uma tipologia das interações transfronteiriça. En C. Zarate (Ed.), Espacios urbanos y ciudades transfronterizas en la Amazonia (pp. 154-166). Universidad Nacional de Colombia Sede Amazonia/ Instituto Amazónico de Imani. https:/ / core.ac.uk/download/pdf/85143005.pdf

Sternberg, C. (2017). Ghetto. En D. Richardson, N. Castree, M. Goodchild, A. Kobayashi, L. Weidong \& R. Marston (Eds.), The international encyclopedia of geography. People, the Earth, environment, and technology (2017). Wiley-Blackwell.

Tapia, M. (2015). Frontera, movilidad y circulación reciente de peruanos y bolivianos en el norte de Chile. Estudios Atacameños, (50), 195-213. https://dx.doi. org/10.4067/S0718-10432015000100010

Tapia, M., Liberona, N. \& Contreras, Y. (2017). El surgimiento de un territorio circulatorio en la frontera chileno-peruana: estudio de prácticas socio-espaciales fronterizas. Revista de Geografía Norte Grande, (66), 117-141. http://dx.doi. org/10.4067/S0718-34022017000100008

Trejos, L. (2015). El lado colombiano de la frontera colombo-brasilera. Una aproximación de la categoría de área sin ley. Estudios Fronterizos, 16(31), 39-64. https:/ / doi.org/10.21670/ref.2015.31.a02

Van Kessel, J. (2003). Holocausto al progreso: Los Aymará de Tarapacá. IEcta. 
Valdebenito, F. (2017). Movilidad y espacialidad en la (trans)frontera tacno-ariqueña. Sur peruano y norte chileno. Si Somos Americanos. Revista de Estudios Transfronterizos, 17(1), 39-64. http://dx.doi.org/10.4067/S0719-09482017000100039

Valdebenito, F. \& Navarro, K. (2019). Transformación, reescalamiento y desigualdad urbana contemporánea en Arica (Chile): la toma de Cerro Chuño como caso de (in)justicia espacial. RumbosTS, (19), 145-172. http://revistafacso.ucentral. $\mathrm{cl} /$ index.php/rumbos/article/view/333

Wacquant, L. (2001). Parias urbanos. Marginalidad en la ciudad a comienzos del milenio. Manantial.

Wacquant, L. (2010). Las dos caras de un gueto. Ensayos sobre marginalización y penalización. Siglo Xxi Editores.

Wacquant, L. (2013). Tres premisas nocivas en el estudio del gueto norteamericano. Revista INVI, 28(79), 165-187. http://dx.doi.org/10.4067/S0718-83582013000300006

Zarate, C. (2012). Introducción. En C. Zarate (Ed.), Espacios urbanos y ciudades transfronterizas en la Amazonia (pp. 11-18). Universidad Nacional de Colombia Sede Amazonia/Instituto Amazónico de Imani.

Rodrigo Hidalgo Dattwyler

Chileno. Geógrafo, doctor en geografía por la Universidad de Barcelona. Director del programa de doctorado del Instituto de Geografía de la Pontificia Universidad Católica de Chile. Líneas de investigación: urbanización, neoliberalismo y geografía urbana. Publicación reciente: Hidalgo, R., González, M. \& Vergara, C. (2021). Vivienda y urbanización en la ciudad de Arica: Costa, desierto e integración subsidiaria en la frontera norte de Chile (2000-2019). Diálogo andino, (64), 225-242.

Carlos Vergara Constela

Chileno. Sociólogo, máster en estudios territoriales y de la población (Universidad Autónoma de Barcelona), doctor en geografía (Pontificia Universidad Católica de Chile). Líneas de investigación: geografía urbana, sociología urbana y estudios sociales del deporte.

Miguel Felipe González Rodríguez

Chileno. Profesor de historia y ciencias sociales, magister en estudios latinoamericanos (Universidad de Chile), estudiante de doctorado en geografía (Pontificia Universidad Católica de Chile). Líneas de investigación: políticas de vivienda, migraciones y geografía urbana. 